\title{
Halk Elinde Yetiştirilen Kaz, Ördek ve Hindi Yumurtalarının Bazı Dış Kalite Özelliklerinin İncelenmesi ${ }^{* *}$
}

\author{
Sema ALAŞAHAN ${ }^{1 *}$, Mustafa GARiP ${ }^{2}$, Tamer ÇAĞLAYAN ${ }^{2}$, Cafer Tayyar ATEŞ ${ }^{1}$ \\ ${ }^{1}$ Hatay Mustafa Kemal Üniversitesi, Veteriner Fakültesi Zootekni Anabilim Dalı, 31060 Hatay, Türkiye. \\ ${ }^{2}$ Selçuk Üniversitesi, Veteriner Fakültesi Zootekni Anabilim Dalı, 42003 Konya, Türkiye.
}

\begin{abstract}
Özet: Çalışma kaz, ördek ve hindi kanatı hayvan türlerinin yumurtalarına ait dış kalite özellik değerlerini belirlemek amacıyla yapılmıştır. Çalışmanın materyalini Konya ilinde halk elinde yetiştirilen kaz, ördek ve hindilerden temin edilen toplam 440 adet kaz ( $n=117),(n=260)$ ördek ve hindi $(n=63)$ yumurtası oluşturmuştur. Her bir yumurta bireysel olarak tartılmış olup yumurta boyu ve eni saptanmıştır. Ölçümle belirlenen bu üç değer kullanılarak matematiksel denklemler yardımıyla yumurta dış kalite özellik değerleri tespit edilmiştir. Yumurtaların şeklini tanımlamada şekil indeksi ve elongasyon değerleri kullanılmıştır. Kaz, ördek ve hindi yumurta kabuk özellikleri olarak kabuk ağırlığı (11.32 ve $11.23 \mathrm{~g}$; 5.69 ve $5.71 \mathrm{~g}$; 5.31 ve $5.33 \mathrm{~g}$ ), kabuk kalınlığı ( 0.45 ve $0.48 \mathrm{~mm} ; 0.35$ ve $0.35 \mathrm{~mm} ; 0.32$ ve $0.34 \mathrm{~mm})$ ve kabuk yoğunluğu $\left(2.08 \mathrm{~g} / \mathrm{cm}^{3} ; 2.06 \mathrm{~g} / \mathrm{cm}^{3}\right.$; $2.06 \mathrm{~g} / \mathrm{cm}^{3}$ ) sırasıyla belirlenmiştir. Ayrıca yumurta kabuk yüzey alanı ve yumurta kütlesi saptanmıştır. Kaz, ördek ve hindi yumurtalarına ait şekil indeksi ve elongasyon değerleri sırasıyla $\% 68,13 \pm 0.39$ ve $1.47 \pm 0.01, \% 71,76 \pm 0.19$ ve $1.40 \pm 0.00$, $\% 72,53 \pm 0.32$ ve $1.38 \pm 0,01$ olarak tespit edilmiştir. Bu çalışmada, yumurta ağırlığı, yumurta boyu ve eni baz alınarak bazı küçük beden yapısına sahip kanatlı hayvanların yumurta özellikleri için belirlenen matematiksel formüller yardımıyla kaz, ördek ve hindi kanatlı türlerinin yumurta dış kalite özellik değerleri hesaplanmıştır.
\end{abstract}

Anahtar Kelimeler: Kaz yumurtası, Ördek yumurtası, Hindi yumurtası, Dış kalite özelikleri, Elongasyon.

\section{Examination of Some External Quality Traits of Goose, Duck and Turkey Eggs in Public Farms}

\begin{abstract}
The present study aimed at the determination of certain external quality traits of goose, duck and turkey eggs. A total of 440 eggs obtained from geese $(n=117)$, ducks $(n=260)$ and turkeys $(n=63)$, which were raised by the local people of Konya province, constituted the material of the study. Each egg was weighed individually, and the length and width of the eggs were determined. Using these three measurements and mathematical equations, the external quality traits of the eggs were determined. For defining the shape of the eggs, both the shape indices and elongation values were utilised. Goose, duck and turkey egg shell traits determined, included egg shell weight (11.32 and $11.23 \mathrm{~g} ; 5.69$ and $5.71 \mathrm{~g} ; 5.31$ and $5.33 \mathrm{~g}$ ), egg shell thickness $(0.45$ and $0.48 \mathrm{~mm} ; 0.35$ and $0.35 \mathrm{~mm} ; 0.32$ and $0.34 \mathrm{~mm})$ and egg shell density $\left(2.08 \mathrm{~g} / \mathrm{cm}^{3} ; 2.06 \mathrm{~g} / \mathrm{cm}^{3 ;}\right.$ $2.06 \mathrm{~g} / \mathrm{cm}^{3}$ ), respectively. Furthermore, egg shell surface area and egg mass were calculated. Descriptive statistics were used to determine the mean and standard errors for these types of poultry eggs. The shape indices and elongation values detected for goose, duck and turkey eggs were $68.13 \pm 0.39 \%$ and $1.47 \pm 0.01,71.76 \pm 0.19 \%$ and $1.40 \pm 0.00$, and $72.53 \pm 0.32 \%$ and $1.38 \pm 0.01$, respectively. In this study, the external quality traits of goose, duck and turkey eggs were calculated using mathematical formulae established for small poultry species on the basis of egg weight, egg length and egg width values.

Keyword: Geese egg, Duck egg, Turkey egg, External quality traits, Elongation.
\end{abstract}

\section{Giriş}

Kanatlı hayvan yetiştiriciliği üretim kolunda büyük ticari üretim işletmeleri tavuk yetiştiriciliğinde aktif çalışırken kaz, ördek ve hindi kanatlı türlerinin yetiştiriciliği küçük aile işletmesi şeklinde sürdürülmektedir. Kaz, ördek ve hindi yetiştiriciliği genelde et üretimi amacıyla yapılmaktadır. Dolayısıyla bu kanatlı türlerinin yumurtaları döllü olup genelde sürü devamlılığı için yavru üretiminde kullanılmaktadır (Karabulut ve ark., 2017; Taşkın ve ark., 2017).

Kaz ve ördek yumurtalarının kabuk yüzeyi beneksiz olup hindi yumurtası ise küçük ve aynı boyutta yumurta yüzeyine homojen olarak dağılmış beneklere sahiptir. Ayrıca hindi ve ördek yumurtalarında kut ve sivri uç ayrımı kolay yapılmakta, kaz yumurtasında ise uçların ayrımı oldukça zordur. Ördek yumurta verimi yıl boyu olup bir üretim yılında (yaklaşık 10 ay) ortalama 150-200 adet arasında yumurta elde edilmektedir (Narahari ve ark., 1991). Kaz yumurta üretimi mevsimsel olup gün uzunluğunun artışı ile yumurta verimi başlamaktadır (Kırmızıbayrak ve ark., 2016). Hindi kanatlı türünde yılık yumurta verimi ortalama 60 100 adet arasında olduğu ifade edilmektedir (Erişir ve Yıldız, 2000).

Kaz, ördek ve hindi kanatlı türlerinin yumurtalarının kalite özellik değerleri bütün yumurta ağırlığı, şekil özellikleri, ak ve sarı özelliklerinden oluşmaktadır. Yumurta şekil özellik değerleri yumurta boyu ve eni kullanılarak hesaplanan yumurta şekil indeksi ve elongasyondan (uzama) oluşmaktadır. Uzama yumurtanın boyunun baz alındığı bir şekil özelliğidir. Uzama değeri, yumurta ekvator bölge başlangıç çizgisi ile sivri uç 
taban nokta aralığına göre yumurta şeklini tanımlamaktadır. Yumurtaların iç kalite özellik değerleri ise koyu akı yükseklik ve çaplarının, sarı yükseklik ve çapının ölçümü ile hesaplanan ak indeksi, haugh birimi ve sarı indeksi olarak ifade edilmektedir (Türkoğlu ve Sarıca, 2009). Yumurta verimi düşük olan bu kanatlı türlerinde yumurtaların özellikle yumurta bütünlüğü bozulmadan kalite özelliklerinin belirlenmesi önemlidir. Yumurta, kanatlı hayvanlarda üreme kaynağıdır. Bu nedenle kuluçkalık yumurtaların bütünlüğünün bozulmaması neslin devamlılığı için önem arz etmektedir. Yumurta bütünlüğünü bozmadan ölçülebilen yumurta ağırlığı, yumurta boyu ve eni değerleri kullanılarak çeşitli matematiksel formüller geliştirilmiştir (Ar ve ark., 1974; Rahn ve ark., 1979).

$\mathrm{Kaz}$, ördek ve hindi kanatlı türlerinin yumurtaları ağırlığı bakımından farklııı göstermekte olup bu türler içerisinde yumurta ağırlığı en yüksek olan kaz yumurtasıdır. Kazlarda yumurta ağırlığı ve şekil indeksi Saatci ve ark. (2005) tarafından Kars bölgesinde yetiştirilen Türk kazlarının yumurtaları için ortalama $148.43 \mathrm{~g}$ ve $\% 66.80$, Rabsztyn ve ark. (2010) tarafından Zatorska kazlarının yumurtalarında ortalama $164.97 \mathrm{~g}$ ve $\% 68.82$ olarak bildirilmiştir. Rahman ve ark. (2010) tarafından Bangladeş kıyı bölgesinde yetiştirilen Khaki Campbell, Jinding ve Deshi kazlarında yumurta ağırlığı ve şekil indeksi değerlerini verilen sırayla $65.15 \mathrm{~g}$ ve $\% 71.29,64.38 \mathrm{~g}$ ve $\% 71.59,58.93 \mathrm{~g}$ ve \%68.58 olduğunu saptamışlardır. Pekin ördek yumurtası için Al-Obaidi ve ark. (2016) tarafından 91.89 g yumurta ağırlığı ve \%63.47 şekil indeksi değerleri ifade edilmiştir. Hindi yumurtalarının ağırlığı ve şekil indeksi Mróz ve ark. (2014) tarafından yumurtlama mevsiminin 5 haftasında $89.86 \mathrm{~g}$ ve $\% 72.60$ olarak bulunmuştur.

Yumurta dış kalite özelliklerinden kabuk kalınlığı ve ağırlığı değerleri kaz, ördek ve hindi yumurtalarında farlılık göstermektedir. Kars ilindeki yerli kaz yumurta kabuk ağırlığı ortalama $20.37 \mathrm{~g}$ ve kabuk kalınlığı $0.72 \mathrm{~mm}$ olarak bildirilmiştir (Saatci ve ark., 2002). Kaz yumurta kabuk ağırlığı ve kalınlığı Tilki ve İnal (2004) tarafından INRA kaz ırkı yumurtası için $19.0 \mathrm{~g}$ ve $0.52 \mathrm{~mm}$; Amao ve Olugbemiga (2016) tarafından Nijerya'nın güney bölgesinde yetiştirilen kaz ırkı yumurtasında $6.20 \mathrm{~g}$ ve $0.42 \mathrm{~mm}$ olarak saptamışlardır. Ördek yumurta kabuk ağırlığı ve kalınlığı için $7.9 \mathrm{~g}$ ve $0.387 \mathrm{~mm}$ (Kokoszynkski ve ark., 2007) ve $7.60 \mathrm{~g}$ ve $0.49 \mathrm{~mm}$ (Amao ve Olugbemiga, 2016) olduğunu ifade etmişlerdir. Hristakieva ve ark. (2017b) tarafından Bronz hindi yumurta kabuk ağırlığı 6.73 g ve kabuk kalınlığı $0.39 \mathrm{~mm}$ olarak saptanmıştır.

$\mathrm{Bu}$ çalışmada, Konya ilinde halk elinde yetiştirilen kaz, ördek ve hindi kanatlı türlerinin kuluçkalık yumurtalarının temel dış kalite özellikleri çeşitli matematik modeller kullanarak yumurta kabuk bütünlüğü bozulmadan incelenmiştir.

\section{Materyal ve Metot}

$\mathrm{Bu}$ çalışma Selçuk Üniversitesi Veteriner Fakültesi Hayvancılık Araştırma ve Uygulama Çiftliği Alternatif Kanatlı Ünitesinde yürütülmüştür. Deneme materyali yumurtalar Konya ilinde halk elinde yetiştirilen ancak üniteye kuluçka için getirilen kaz (117 adet), ördek (260 adet) ve hindi (63 adet) türlerinin kuluçkalık yumurtalarından oluşmuştur. Üniteye getirilen kuluçkalık yumurtalar ağırlık değerini etkileyecek kabuk kusuru olan yumurtalar ayrıldıktan sonra kalan sağlam yumurtaların yumurta ağırlıkları belirlenmiştir. Yumurta uzunluk ölçümünde ise yumurta bütünlüğü zarar görmeyen yumurtalar kullanılmıştır.

Her bir türe ait kuluçkalık yumurtalar gözle muayene edilerek bireysel ağırıkları elektronik terazi yardımıyla, yumurta boyu ve eni değerleri ise elektronik kumpas ile ölçülerek belirlenmiştir. Ölçümle belirlenen değerler kullanılarak diğer dış kalite özellikleri aşağıdaki matematiksel formüller yardımıyla belirlenmiştir (Ar ve ark., 1974; Hoyt, 1979; Rahn ve ark., 1979; Saatci ve ark., 2002; Narushin, 2005).

$$
\begin{aligned}
& \text { YA: Yumurta Ağırlığı; L: Yumurta Boyu; B: Yumurta Eni; I: Kuluçka } \\
& \text { Süresi } \\
& \text { Kütle }(K, g)=54.19 \times\left(L \times B^{2}\right) \\
& \text { Kabuk Yüzey Alanı }\left(\mathrm{S}, \mathrm{cm}^{2}\right) \\
& \mathrm{S}_{1}=4.835 \times(\mathrm{YA})^{0.662} \\
& \mathrm{~S}_{2}=4.76 \times \mathrm{W}^{0.658} \\
& \mathrm{~S}_{3}=3.9782 \times(\mathrm{YA})^{0.7056} \\
& S_{4}=(3.155-0.0136 \times L+0.0115 \times B) \times L \times B \\
& S_{5}=(0.9658 \times(B / L)+2.1378) \times L \times B \\
& \text { Şekil indeksi (Şi, \%) } \\
& \text { Şi }=(B / L) \times 100 \\
& \text { Elongasyon ( } E \text {, Uzama) } \\
& E_{1}=L / B \\
& E_{2}=1.3 \times(Y A)^{0.014} \\
& \text { Kabuk Ağırlığı (KA, g) } \\
& \mathrm{KA}_{1}=4.82 \times 10^{-2} \times(\mathrm{YA})^{1.132} \\
& \mathrm{KA}_{2}=0.0524 \times(\mathrm{YA})^{1.113} \\
& \text { Kabuk Kalınlığı (KK, mm) } \\
& \mathrm{KK}_{1}=5.126 \times 10^{-3} \times(\mathrm{YA})^{0.456} \\
& \mathrm{KK}_{2}=0.0546 \times(\mathrm{YA})^{0.441} \\
& \text { Kabuk yoğunluğu (KY, } \mathrm{g} / \mathrm{cm}^{3} \text { ) } \\
& K Y=1.945 \times(Y A)^{0.01} \\
& \text { Kabuk Gözenek Sayısı (KGS, adet) } \\
& \mathrm{KGS}_{1}=1041 \times(\mathrm{YA})^{0.504} \\
& \mathrm{KGS}_{2}=304 \times(\mathrm{YA})^{0.767} \\
& \mathrm{KGS}_{3}=3520 \times(\mathrm{YA} / \mathrm{I}) \\
& \text { Hacim }\left(\mathrm{V}, \mathrm{cm}^{3}\right) \\
& V_{1}=0.525 \times L \times B^{2} \\
& \mathrm{~V}_{2}=2.854 \times \mathrm{L} \times \mathrm{B} \\
& V_{3}=(0.6057-0.0018 \times B) \times L \times B^{2} \\
& V_{4}=(0.452+0.069 \times(L / B)) \times L \times B^{2} \\
& V_{5}=0.515 \times L^{2} \times B^{2}
\end{aligned}
$$

Çalışmadan elde edilen verilerin değerlendirilmesinde SPSS 21.0 paket programından yararlanılmıştır. Her kanatlı grubuna ait yumurtalar için elde edilen verilerden tanımlayıcı istatistik yapılmıştır. 


\section{Bulgular}

Kaz, ördek ve hindi yumurtalarında ölçüm ve matematiksel formüllerle hesaplanan yumurta özellik değerlerine ait istatistiksel sonuçlar Tablo16 'da sunulmuştur.

Kaz, ördek ve hindi yumurtalarının kabuk yüzey alanları farklı formüller yardımıyla hesaplanmış olup Tablo 2'de sunulmuştur. Kabuk yüzey alan değeri kaz yumurtası için $\mathrm{KYA}_{4}\left(112.73 \mathrm{~cm}^{2}\right)$, ördek yumurtası için $\mathrm{KYA}_{1}\left(78.54 \mathrm{~cm}^{2}\right)$ ve hindi yumurtası için ise $\mathrm{KYA}_{5}\left(77.84 \mathrm{~cm}^{2}\right)$ değerlerinde yüksek bulunmuştur.

Tablo 1. Farklı kanatlı tür yumurtalarında büyüklük değerleri $(\mathrm{X} \pm \mathrm{Sx})$.

\begin{tabular}{lcc}
\hline & & \\
Türler & Yumurta Ağı̆lı̆ı̆ (g) & Kütle (g) \\
\cline { 2 - 3 } Kaz & Tartım & $\mathbf{K}$ \\
& $124.11 \pm 1.60$ & $121.16 \pm 1.74$ \\
Ördek & $n=117$ & $n=117$ \\
& $67.58 \pm 0.53$ & $62.87 \pm 0.50$ \\
Hindi & $n=219$ & $n=260$ \\
& $63.57 \pm 0.93$ & $66.44 \pm 1.10$ \\
& $n=57$ & $n=63$ \\
\hline
\end{tabular}

Kaz, ördek ve hindi yumurtalarından ölçülen yumurta boyu ve eni kullanılarak hesaplanana yumurta kütle değerleri kaz ve ördek yumurtası için tartım ağırlığından düşük olurken hindi yumurtalarında yüksek bulunmuştur (Tablo 1).

Tablo 2. Farklı kanatlı tür yumurtalarında kabuk yüzey alan değerleri, $(\mathrm{X} \pm \mathrm{Sx})$

\begin{tabular}{lccccc}
\hline & \multicolumn{5}{c}{ Kabuk Yüzey Alanı $\left(\mathrm{cm}^{2}\right)$} \\
Türler & $S_{1}$ & $S_{2}$ & $S_{3}$ & $S_{4}$ & $S_{5}$ \\
\hline Kaz & $11.38 \pm 0.99$ & $113.35 \pm 0.95$ & $119.19 \pm 1.07$ & $112.73 \pm 0.97$ & $116.82 \pm 1.12$ \\
& $n=117$ & $n=117$ & $n=117$ & $n=117$ & $n=117$ \\
Ördek & $78.54 \pm 0.41$ & $76.03 \pm 0.39$ & $77.66 \pm 0.43$ & $75.03 \pm 0.37$ & $75.10 \pm 0.40$ \\
& $n=219$ & $n=219$ & $n=219$ & $n=260$ & $n=260$ \\
Hindi & $75.43 \pm 0.73$ & $73.04 \pm 0.70$ & $74.39 \pm 0.77$ & $77.61 \pm 0.81$ & $77.84 \pm 0.86$ \\
& $n=57$ & $n=57$ & $n=57$ & $n=63$ & $n=63$ \\
\hline
\end{tabular}

Tablo 3. Farklı kanatlı tür yumurtalarında şekil özellik değerleri $(\mathrm{X} \pm \mathrm{Sx})$.

\begin{tabular}{lccccc}
\hline \multirow{2}{*}{ Türler } & $\mathbf{L}(\mathbf{m m})$ & $\mathbf{B}(\mathbf{m m})$ & $\begin{array}{c}\text { Şekil } \\
\text { indeksi }(\%)\end{array}$ & \multicolumn{2}{c}{ Elongasyon } \\
& \multicolumn{3}{c}{} & \multicolumn{3}{c}{ Ölçüm } & Şi & $\mathrm{E}_{1}$ & $\mathrm{E}_{2}$ \\
\cline { 2 - 6 } Kaz & $78.39 \pm 0.52$ & $53.23 \pm 0.23$ & $68.13 \pm 0.39$ & $1.47 \pm 0.01$ & $1.39 \pm 0.00$ \\
& $n=117$ & $n=117$ & $n=117$ & $n=117$ & $n=117$ \\
Ördek & $60.79 \pm 0.18$ & $43.58 \pm 0.13$ & $71.76 \pm 0.19$ & $1.40 \pm 0.00$ & $1.38 \pm 0.00$ \\
& $n=260$ & $n=260$ & $n=260$ & $n=260$ & $n=219$ \\
Hindi & $61.48 \pm 0.40$ & $44.54 \pm 0.24$ & $72.53 \pm 0.32$ & $1.38 \pm 0.01$ & $1.38 \pm 0.00$ \\
& $n=63$ & $n=63$ & $n=63$ & $n=63$ & $n=57$ \\
\hline
\end{tabular}

Tablo 4. Farklı kanatlı tür yumurtalarında kabuk özellik değerleri $(\mathrm{X} \pm \mathrm{Sx})$.

\begin{tabular}{cccccc}
\hline & Kabuk ağırlı̆ı (g) & \multicolumn{2}{c}{ Kabuk kalınlı̆̆ı $(\mathbf{m m})$} & $\begin{array}{c}\text { Kabuk } \\
\text { yoğunluğu } \\
\left(\mathbf{g} / \mathbf{c m}^{3}\right)\end{array}$ \\
\cline { 2 - 6 } Türler & $\mathbf{K A}_{1}$ & $\mathbf{K A}_{2}$ & $\mathbf{K K}_{1}$ & $\mathbf{K K}_{2}$ & $\mathbf{K Y}_{1}$ \\
\hline Kaz & $11.32 \pm 0.17$ & $11.23 \pm 0.16$ & $0.45 \pm 0.00$ & $0.46 \pm 0.00$ & $2.08 \pm 0.00$ \\
& $n=117$ & $n=117$ & $n=117$ & $n=117$ & $n=117$ \\
Ördek & $5.69 \pm 0.05$ & $5.71 \pm 0.05$ & $0.35 \pm 0.00$ & $0.35 \pm 0.00$ & $2.06 \pm 0.00$ \\
& $n=219$ & $n=219$ & $n=219$ & $n=219$ & $n=219$ \\
Hindi & $5.31 \pm 0.09$ & $5.33 \pm 0.09$ & $0.32 \pm 0.00$ & $0.34 \pm 0.00$ & $2.06 \pm 0.00$ \\
& $n=57$ & $n=57$ & $n=57$ & $n=57$ & $n=57$ \\
\hline
\end{tabular}

İncelenen kanatlı tür yumurtalarının şekil özellikleri Tablo 3'de verilmiştir. Kaz yumurta boyu (78.39 $\mathrm{mm}$ ) ve eni $(53.23 \mathrm{~mm}$ ) değerleri ördek ve hindi yumurta boyu ve eni değerlerinden yüksek iken şekil indeksi (\%68.13) değerinin düşük olduğu saptanmıştır. Kaz, ördek ve hindi yumurtalarında kabuk özellik değerleri olarak kabuk ağırlığı, kabuk kalınlığı, kabuk yoğunluğu ve kabuk gözenek sayıları belirlenmiştir (Tablo 4 ve Tablo 5) İncelenen kabuk özellik değerleri bakımından kaz yumurtalarının daha yüksek değerlere sahip olduğu saptanmıştır.

Tablo 5. Farklı kanatlı tür yumurtalarında kabuk gözenek sayısı.

\begin{tabular}{lccc}
\hline & \multicolumn{3}{c}{ Kabuk gözenek sayısı (adet) } \\
\cline { 2 - 4 } Kürler & KGS $_{\mathbf{1}}$ & KGS $_{\mathbf{2}}$ & KGS $_{\mathbf{3}}$ \\
\hline \multirow{3}{*}{ Ördek } & 11796 & 12249 & 15603 \\
& $\mathrm{n}=117$ & $\mathrm{n}=117$ & $\mathrm{n}=117$ \\
Hindi & 8689 & 7688 & 8496 \\
& $\mathrm{n}=219$ & $\mathrm{n}=219$ & $\mathrm{n}=219$ \\
& 8426 & 7337 & 7991 \\
& $\mathrm{n}=57$ & $\mathrm{n}=57$ & $\mathrm{n}=57$ \\
\hline
\end{tabular}

Ancak ördek ve hindi yumurtalarının özellikle kabuk kalınlığı $(0.35 \mathrm{~mm}$ ve $0.32-0.34 \mathrm{~mm})$ ve kabuk yoğunluğu $\left(2.06 \mathrm{~g} / \mathrm{cm}^{3}\right.$ ve $\left.2.06 \mathrm{~g} / \mathrm{cm}^{3}\right)$ bakımından birbirine çok yakın değerlerde olduğu bulunmuştur.

Tablo 6. Farklı kanatlı tür yumurtalarında hacim değerleri $(X \pm S x)$.

\begin{tabular}{cccccc}
\hline & \multicolumn{5}{c}{ Hacim $\left(\mathrm{cm}^{3}\right)$} \\
\cline { 2 - 6 } Türler & $\mathbf{V}_{1}$ & $\mathbf{V}_{\mathbf{2}}$ & $\mathbf{V}_{\mathbf{3}}$ & $\mathbf{V}_{\mathbf{4}}$ & $\mathbf{V}_{5}$ \\
\hline Kaz & $117.38 \pm 1.69$ & $119.35 \pm 1.22$ & $113.86 \pm 1.54$ & $123.84 \pm 1.83$ & $115.14 \pm 1.66$ \\
& $n=117$ & $n=117$ & $n=117$ & $n=117$ & $n=117$ \\
Ördek & $60.91 \pm 0.48$ & $75.72 \pm 0.40$ & $61.12 \pm 0.46$ & $63.61 \pm 0.50$ & $60.91 \pm 0.48$ \\
& $n=260$ & $n=260$ & $n=260$ & $n=260$ & $n=260$ \\
Hindi & $64.37 \pm 1.07$ & $78.29 \pm 0.88$ & $64.38 \pm 1.01$ & $67.11 \pm 1.12$ & $63.15 \pm 1.05$ \\
& $n=63$ & $n=63$ & $n=63$ & $n=63$ & $n=63$ \\
\hline
\end{tabular}

Kaz, ördek ve hindi yumurtalarının hacim değerleri ölçümle belirlenen yumurta boyu ve eni değerleri baz alınarak beş farklı denklem kullanılarak hesaplama sonuçları Tablo 6'da sunulmuştur. En yüksek hacim değeri kaz yumurtası için $123.84 \mathrm{~cm}^{3}$; ördek yumurtası için $75.72 \mathrm{~cm}^{3}$ ve hindi yumurtası için ise $78.29 \mathrm{~cm}^{3}$ olduğu saptanmıştır.

\section{Tartışma}

Genotip, yumurtalama mevsimi, yaş, besleme ve aydınlatma gibi faktörlerin etkisinde olan yumurta ağırlığının tartım ve denklem değerleri kaz yumurtasında 124.11 ve $121.16 \mathrm{~g}$, ördek yumurtasında 67.58 ve $62.87 \mathrm{~g}$ ve hindi yumurtaları için 63.57 ve $66.44 \mathrm{~g}$ olarak saptanmıştır (Tablo 1). Çalışmada saptanan kaz yumurta ağırlık değerlerinin Arslan ve Saatci (2003)'nin Kars yöresinde yetiştirilen 1 ve 2 yaşlı yerli kaz yumurta ağırlığı (128.85 ve $148.15 \mathrm{~g}$ ) ve Brun ve ark. (2003) tarafından INRA kaz yumurta ağırlığı (149.4 - 147.8 g) değerlerinden düşük olduğu gözlenmiştir (Saatci ve ark., 2002; Tilki ve İnal, 2004; Mazanowski ve ark., 2005). Yuan ve ark.'nın (2013) yaptıkları bir çalışmada kabuk özelliğine göre çizgili ve normal yumurta olarak sınıflandırılmış Pekin ördeği yumurtalarının ağırlıkları 94.60 ve $97.31 \mathrm{~g}$; Amao ve Olugbemiga (2016) tarafından Nijarya'nın güney bölgesinde yetiştirilen ördeklerin yumurta ağırlığını $70.45 \mathrm{~g}$ olup çalışma sonuçlarından yüksek olduğu gözlenmektedir. Hindi yumurta ağırlığı ile ilgili 
birçok çalışma sonuç değerlerinin çalışma sonucundan yüksek olduğu görünmektedir (Hristakieva ve ark., 2011; Anna Anandh ve ark., 2012; Mroz ve ark., 2014; Anna Anandh ve Richard Jagatheeesan, 2015). Bildirilen yumurta ağırlık değerlerinin çalışma sonuçlarından farklı olması genotip özelliklerinden ve yetiştirme koşulları farklılığından olabilir.

Kanatlı hayvan türlerinin yumurta şekil özellik değerleri yumurta boyu ve eni değerleri kullanılarak hesaplanan şekil indeksi ve uzama (elongasyon) değerleri olarak belirlenmektedir. Yumurtaların şekil tanımlamasında yumurta şekil indeksi yaygın şekilde tercih edilirken uzama değeri az tercih edilmektedir. Çalışmamızda kaz, ördek ve hindi yumurtalarında şekil indeksi ve uzama değerleri verilen sırayla $\% 68.13$ ve $1.47, \% 71.76$ ve $1.40, \% 72.53$ ve 1.38 olarak saptanmıştır (Tablo 3). Çalışma sonuçları kaz, ördek ve hindi yumurtalarının şekil özellikleri ile ilgili yapılan birçok araştırma sonuçlarından düşük değerde tespit edilmiştir (Tilki ve İnal, 2004; Rabsztyn ve ark., 2010; Kavitha ve ark., 2017; Zhang ve ark., 2017). Yumurta boyu ve eni değerlerini belirleme işlemi için özel tasarlanmış ölçüm makinaları yoktur. Dolayısıyla ölçüm yeri bireysel ölçüm hatalarına açık olup şekil özellik değerlerinde farklılıklar oluşturacağı unutulmamalıdır.

Çalışmada kaz (11.32 ve 11.23 g), ördek (5.69 ve $5.71 \mathrm{~g}$ ) ve hindi (5.31 ve $5.33 \mathrm{~g}$ ) yumurtaları için tespit edilen kabuk ağırlıkları birbirinden farklı olup büyük yumurta ağırlığına sahip kaz yumurtası için kabuk ağırlığının da fazla olduğu saptanmıştır (Tablo 4). Kaz yumurta kabuk ağırlığı Saatci ve ark. (2002) tarafından $20.37 \mathrm{~g}$ ve Tilki ve İnal (2004) tarafından 18.7, 18.4 ve 20.1 g; ördek yumurta kabuk ağırlığı Balkan ve Biricik (2008) tarafından $7.97 \mathrm{~g}$ ve Yaun ve ark. (2013) tarafından 8.24 ve $8.72 \mathrm{~g}$; hindi yumurta kabuk ağırlığı Adeyeye (2009) tarafından $8.20 \mathrm{~g}$ ve Galic ve ark. (2018) tarafından 9.20 ve $10.03 \mathrm{~g}$ olarak bildirilmişlerdir. Bildirilen bu kabuk ağırlığı değerlerinin çalışmanın sonuçlarından yüksek olduğu gözlenmiştir. Kabuk ağırlığındaki farklılıklar ırk ve yumurta ağırlık farklılıklarından olabilir.

Yumurta kabuk kalınlığı yumurtanın sivri, ekvator ve küt bölgesinde farklı değerlerde değişmektedir. Kaz, ördek ve hindi yumurtaları büyük hacimli ve kabuk kalınlığı fazla olan yumurtalardır. Çalışma sonucunda yumurta ağırlığı yüksek olan kaz yumurtasının ortalama kabuk kalınlığı (0.45 ve $0.46 \mathrm{~mm}$ ) da ördek (ortalama 0.35 $\mathrm{mm}$ ) ve hindi (ortalama 0.32 ve $0.34 \mathrm{~mm}$ ) yumurta kabuk kalınlığından yüksek bulunmuştur. Kaz, ördek ve hindi yumurta kabuk kalınlığı için saptanan bu değerler bu kanatlı tür yumurtaları için bildirilen çoğu çalışma sonuçlarından yüksek olmuştur (Kokoszynski ve ark., 2007; Hristakieva ve ark., 2009; Bingöl ve ar., 2016; Galic ve ark., 2018).
Çalışmada kabuk gözenek sayısı kaz (11796, 12249 ve 15603 adet), ördek (8689, 7688 ve 8496 adet) ve hindi (8426, 7337 ve 7991 adet) yumurtalarında saptanmıştır. Kabuk gözenek sayısı kaz yumurtasında Mazanowsk ve Adamski (2006) tarafından ortalama 12726 adet; ördek yumurtasında Balkan ve Biricik (2008) tarafından 9625 adet ve hindi yumurtası için Hristakieva ve ark. (2017a) tarafından 34 haftalık yaştaki bronz hindi yumurtasında 4242.79 adet ve 46 haftalık yaştaki bronz hindi yumurtasında ise 4871.12 adet olarak bildirilmiştir. Kaz ve ördek yumurtalarının kabuk gözenek sayıları için bildirilen değerler çalışma sonuçlarına yakın olurken hindi yumurtası için bildirilen değerler çalışma sonuçlarından düşük olduğu gözlenmektedir. Kabuk gözenek sayısındaki bu farklılıklar çalışmalardaki yumurtaların büyüklüklerinin farklılığı yanında kabuk gözenek belirleme teknik farklılıklarından kaynaklanıyor olabilir.

\section{Sonuç}

Bu çalışmanın sonucunda, kaz, ördek ve hindi yumurtalarında ölçümle elde edilen yumurta ağırlı̆̆ı, yumurta boyu ve yumurta eni değerleri kullanılarak bazı matematiksel formüller yardımıyla diğer dış kalite ölçütleri tespit edilmiştir. Ayrıca, çalışmada belirlenen özellikler için başka araştırmacıların çalışma sonuçları ile karşılaştırıldığında yumurta kırılarak tespit edilebilen bazı kalite özellik değerlerinin matematiksel formüller kullanılarak hesaplanan değerlere yakınlığını göstermesi adına elde edilen sonuçlar önem arz etmektedir.

\section{Kaynaklar}

Adeyeye El, 2009: Comparative study on the characteristics of egg shells of some bird species. Bulletin of The Chemical Society of Ethiopia, 23(2), 159-166.

Al-Obaidi FA and Al-Shadeedi SMJ, 2016: Comparison study of egg morphology, component and chemical composition of mallard duck and domestic peking duck. Journal of Bio Innovation, 5(4), 555-562.

Amao SR, Olugbemiga KS, 2016: A study of quality traits of duck and goose eggs selected from different areas of oyo metropolis, southern quine zone of Nigeria. Continental J Agricultural Science, 10(1),1-7.

Amao SR, Oyewumi OS, Ajayi JA, 2013: Effect of cage versus plastic box housing on the growth traits of Achatina achatina snails reared in southern guinea zone Nigeria. International Journal of Applied Research and Technology, 2(7), 53-58.

Anna Anandh M, Richard Jagatheesan PN, Senthil Kumar P, Paramasivam A, Rajarajan G, 2012: Effect of rearing systems on reproductive performance of turkey. Veterinary World, 5(4), 226-229.

Anna Anandh M, Richard Jagatheesan PN, 2015: Reproductive performance of beltsville small white 
and broad breasted bronze turkeys (Meleagris gallopavo) under hot humid climatic condition. Indian Journal of Animal Research, 49(6), 847-850.

Ar A, Paganelli CV, Reeves RB, Greene DG, Rahn H, 1974: The avian egg: water vapor conductance, shell thickness and functional pore area.Condor,76,153-158.

Arslan C, Saatci M, 2003: Kars yöresi yerli kazlarının yumurta verimi ve kuluçka özellikleri. Turkish Journal Veterinary and Animal Sciences, 27(6), 1361-1365.

Balkan $M$ ve Biricik $M, 2008$ : Main egg characteristics in the peking duck. Dicle Üniversitesi Ziya Gökalp Eğitim Fakültesi Dergisi, 11, 142-150.

Bingöl SA, Deprem T, Karadağ Sarı E, Koral Taşçı S, Aslan Ş, 2016: Comparison between goose (Anser anser) and chicken (Gallus gallus domesticus) eggshells during embryonic development by scanning electron microscopy. Kafkas Üniversitesi Veteriner Fakültesi Dergisi, 22 (6): 937-943.

Brun JM, Delaunay I, Sellıer N, Alletru B, Rouvier R, TixierBoichard M, 2003: Analysis of laying traits in first cycle geese in two production systems. Animal Research, 52, 125-140.

Erişir Z, Yıldız N, 2000: Bronz hindilerde damızlık yaşının kuluçka sonuçlarına etkileri. Yüzüncü Yıl Üniversitesi Veteriner Fakültesi Dergisi, 11(2), 87-89.

Galic A, Pliestic S, Janjecic Z, Bedekovic D, Filipovic D, Kovacev I, Copec K, 2018: Some physical, morphological, and mechanical characteristics of turkey (meleagris gallopavo) eggs. Brazilian Journal of Poultry Science, 20(2), 317-324.

Hristakieva P, Lalev M, Oblakova M, Mincheva N, Ivanova I, 2011: Effect of storage duration on the quality of hatchingturkey eggs.ArchivaZootechnica,14(3),57-65.

Hristakieva P, Oblakova M, Lalev M, 2009: Incubation and vital morphological traits in eggs from age-related turkeys. Trakia Journal of Sciences, 7(1), 63-67.

Hristakieva P, M. Oblakova, N. Mincheva, M. Lalev, K. Kaliasheva, 2017a: Evaluation of some eggshell parameters during the embryogenesis in turkeys. Slovak Journal of Animal Science, 50(1), 1-6.

Hristakieva P, M. Oblakova, N. Mincheva, M. Lalev, K. Kaliasheva, 2017b: Phenotypic correlations between the egg weight, shape of egg, shell thickness, weight loss and hatchling weight of turkeys. Slovak Journal of Animal Science, 50(2), 90-94.

Hoyt DF, 1979: Practical methods of estimating volume and fresh weight of bird eggs. The Auk, 96, 73-77.

Karabulut O, Ün H, Çamkerten I, Garip M, Bulut G, 2017: Aksaray yöresi kazlarda kuluçka randımanı üzerine araştırmalar. Bahri Dağdaş Hayvancılık Araştırma Dergisi, 6(1), 13-22.

Kavitha K, Manohar Raj G, Vairamuthu S, Ramamurthy N, 2017: Comparative study of egg quality traits in white pekin and indigenous ducks of Tamil Nadu. International Journal of Science, Environment and Technology, 6(6), 3520-3523.

Kırmızıbayrak T, Boğa Kuru B, Yazıcı K, 2016: Kazlarda yumurta verimi ve kalite özellikleri ile kuluçka özellikleri. Turkiye Klinikleri J Reprod Artif InseminSpecial Topics, 2(1), 42-47.

Kokoszynski D, Bernacki Z, Korytkowska H, 2007: Eggshell and egg content traits in peking duck eggs from the P44 reserve flock raised in Poland. Journal of Central European Agriculture, 8, 9-16.
Mazanowski A, Adamsk M, 2006: The structure, chemical composition and time trends of egg quality characteristics in high-producing geese. Archiv fur Geflügelkunde, 70(3), 127-133.

Mazanowski A, Bernacki Z, Kisiel T, 2005: Characteristics of reproductive traits and egg traits of crossbred geese with Graylag ancestry. Journal of Animal and Feed Sciences, 14, 549- 560.

Mróz E, Stępińska M, Krawczyk M, 2014: Morphology and chemical composition of turkey eggs. The Journal of Applied Poultry Research, 23(2), 196-203.

Narahari D, Abdul Mujeer K, Maqbool A, Asha Rajini R, Sundararasu V, 1991: Factors influencing the hatching performance of duck eggs. British Poultry Science, 32(2), 313-318.

Narushin VG, 2005: Egg geometry calculation using the measurements of length and breadth. Poultry Science, 84, 482-484.

Rabsztyn A, Anders K, Dudek M, 2010: Variability, heritability and correlations of egg shape in the Zatorska goose. Journal of Central European Agriculture, 11(4), 433-436.

Rahman MM, Khan MJ, Alam MS, Islam MA, Rana M, 2010: Egg quality characteristics of three genotypes of duck reared in the coastal area of Bangladesh. $J$ Bangladesh Soc Agric Sci Technol 7(3\&4), 97-102.

Rahn H, Ar A, Paganelli CV, 1979: How bird eggs breathe. Scientific American, 240, 46-55.

Saatci M, Yardımcı M, Kaya i, Poyraz Ö, 2002: Kars ili kazlarında bazı yumurta özellikleri. Lalahan Hayvancılık Araştırma Enstitüsü Dergisi, 42 (2), 37-45.

Saatci M, Kırmızıbayrak T, Aksoy AR, Tilki M, 2005: Egg weight, shape index and hatching weight and interrelationships among these traits in native Turkish geese with different coloured feathers. Turk J Vet Anim Sci 29, 353-357.

Taşkın A, Karadavut U, Camcı Ö, 2017: Kırşehir ilindeki damızlık kaz yetiştiriciliğini etkileyen faktörlerin belirlenmesi. Türk Tarım ve Doğa Bilimleri Dergisi, 4(2), 138-144.

Türkoğlu M, Sarıca M, 2009: Tavukçuluk Bilimi: Yetiştirme, Besleme, Hastalıklar. 3. Basım, Bey ofset Matbaacılık, Türkiye, Ankara.

Tilki M, İnal Ş, 2004: Quality traits of goose eggs: 1. Effects of goose age and storage time of eggs. Archiv Geflügelkunde, 68(4), 182-186.

Yuan J, Wang B, Huang Z, Fan Y, Huang C, Hou Z, 2013: Comparisons of egg quality traits, egg weight loss and hatchability between striped and normal duck eggs. British Poultry Science, 54(2), 265-269.

Zhang J, Peng W, Tang W, Wang M, 2017: Experimental study on the geometrical and mechanical properties of goose eggshells. Brazilian Journal of Poultry Science, 19(3), 455-464.

${ }^{* *}$ IV. Ulusal Veteriner Zootekni Kongresinde Poster Olarak Sunulmuştur.

*Yazışma Adresi: Sema ALAŞAHAN

Mustafa Kemal Üniversitesi, Veteriner Fakültesi, Zootekni Anabilim Dalı, 31040 Antakya/Hatay, Türkiye.

e-mail: salasahan@gmail.com 